\title{
A Survey on Freshmen's Perception of Biblical Knowledge in Intercultural Communication
}

\author{
Fengjuan Zhang \\ Correspondence: Fengjuan Zhang, School of Foreign Languages, Soochow University, No.1 Shizi Street, Suzhou \\ 215006, Jiangsu Province, China. E-mail: zfjzsw@yahoo.com.cn
}

Received: August 28, 2012 Accepted: October 22, 2012 Online Published: November 29, 2012

doi:10.5539/ijel.v2n6p31 URL: http://dx.doi.org/10.5539/ijel.v2n6p31

\begin{abstract}
To date, research on the Bible is mainly confined to literature review or argumentation. This article attempts to get a general idea of learners' conception of biblical culture in developing intercultural communicative competence (hereafter referred to as ICC), as well as the current situation of their biblical knowledge. Data analyses in the survey have reported evidence for the positive and upward tendency among the respondents, indicating much interest and willingness to spend more extracurricular time in learning English. This survey also shows that most respondents agreed to the important role of western culture, but they did not fully perceive the important role of biblical knowledge in learning the English language. In addition, data analysis has led to the conclusion that respondents had grasped less biblical knowledge than expected. This explains the possibility and necessity to promote this positive situation. Then, some pedagogical improvements were addressed on how to affect teaching practice by integrating biblical knowledge into teaching materials.
\end{abstract}

Keywords: survey, conception, biblical culture, biblical knowledge, pedagogical improvements

\section{Introduction}

The proportion of empirical research articles on intercultural communication (hereafter referred to as IC) in academic journals has reached no more than $1 \%$, let alone the topic of integrating biblical knowledge into English language teaching (hereafter referred to as ELT). To date, research on the Bible is mainly confined to literature review or argumentation, covering domains of religion, law, architecture, arts, literature, language, etc. After comparing the previous research on IC at home and abroad, domestic scholars strongly advocated more empirical research on IC, and argued that imitating the current linguistic research style would improve the present situation $(\mathrm{Hu}, 2005$; Peng, 2005). What's worse, the disciplinary orientation of research on IC remained confusing in the past two decades of IC research (Zhang, 2010). Zhou et al (2010) provided further evidence with statistic analyses on the publications in six major journals of foreign language studies between 2007 and 2009. Thus, researchers attending the 2010 Chinese Intercultural Disciplinary Development Conference further advocated versatile research methods on IC, by switching to deductive research, empirical research and quantitative research (Zhang, 2010).

Having searched all the major journals of foreign language studies between 2010 and 2012, the author found that only Hu's (2011) empirical research on IC included the key words "intercultural sensitivity" in the title, and no other had touched upon the topic of integrating biblical knowledge into ELT, let alone the data based articles. However, the topic of the Bible has remained a desideratum for decades. Taking these into consideration, this paper attempts to build upon previous work by extending the research into the domain of cultivating ICC in English learners from the perspective of biblical knowledge, with the purpose of improving the learners' intercultural awareness, intercultural sensitivity as well as their communicative competence. However, the first step of the research is to get a general idea of the current situation of learners' attitude to English learning and their biblical knowledge, and their conception of the biblical culture in ICC as well. Thus this survey and its theoretical basis will be illustrated in the following sections.

\section{Theoretical Framework: Biblical Knowledge in ICC}

\subsection{Definitions of ICC}

IC is a field of study about how people from differing cultural backgrounds communicate, in similar and different ways among themselves, and how they endeavor to communicate across cultures. More precisely, IC is 
communication among people whose cultural perceptions and symbol systems are distinct enough to alter the communication event (Samovar et al, 1998, p. 48). And ICC refers to the complex of abilities needed to perform effectively and appropriately when interacting with others who are linguistically and culturally different from oneself. ICC normally evolves over a lengthy and continuing process of acquisition or learning. Damen (1987) argued for the development of IC skills in addition to communicative competence. He addressed that, culture learning being the fifth dimension of language classroom, culture skill is added to the concept of the communicative competence originally including four skills of listening, speaking, reading and writing. With communicative competence as the overarching goal of foreign language acquisition, "culture" has joined the four traditional language skill areas. As a fairly abstract notion, ICC is often assessed by observing and monitoring one's performance in IC, rather than by talking about it only in abstraction.

\subsection{The Bible's Influences on Western Culture and Language}

The process of globalization offers situations where different cultures meet, conflict, and blend together, and ICC is cultivated in this process. However, people from different cultures find it hard to communicate not only due to language barriers but also due to different culture styles. As Hall points out (1976, p. 13-14), "You touch a culture in one place and everything else is affected." Culture includes knowledge, belief, arts, morals, law, custom, other capabilities and habits acquired by man as a member of society, and thus Sapir (1921/2000) defines culture as what a society does and thinks. Culture is learned, and we learn culture from proverbs, folk tales, legends, myths, art and mass media. Culture is based on symbols, and language bridges between culture and symbols. Culture is transmitted from generation to generation through language (Samovar et al, 1998, p. 51). Biblical culture functions as an integrated whole in western societies. The Christian doctrine is the cornerstone of western culture and ideology. No other religion has so changed the world for the better as Christianity has done in the fields of philosophy, law, education, nation, arts and literature whatsoever. Belief in Christianity will influence the work of ethics, social habits, spiritual pursuit and the like. As the symbol for western civilization, the Bible has infiltrated into all fields of superstructure, philosophy, law, history, art, literature, etc. Many basic concepts and principles of western culture have come down from the Bible, the scripture of Christianity. For example, The Ten Commandments, a list of religious and moral imperatives, were written by God and, through Moses, given to the people of Israel, and were destined to shape the morals of the society. Besides, many popular English phrases and expressions have their origins from the Bible. Written more than 2,000 years ago, the Christian doctrine still continues to influence people today.

\subsection{Biblical Knowledge Promotes Effective IC}

As noted earlier, the Bible, the scripture of Christianity, is the literary and artistic heritage of the world. Sufficient knowledge about the Bible contributes to effective IC and ICC, since problems in IC are usually involved in terms of social values, social beliefs, social behaviors and social patterns. Understanding the potential problems in IC and making a conscious effort to overcome these problems are of the same importance. Hence sufficient biblical knowledge promotes effective IC. Let's take Unit 2 Civil-Rights Heroes in Integrated Course Book 3 (English course book for Chinese college students, published by Shanghai Foreign Language Education Press) for example. The biblical references included in this unit are listed as follows:

\section{African-American Moses}

Josiah Henson was confident that the Creator intended all men to be created equal.

Whites were commonly driven by religious conviction.

"The Bible, in bidding us to feed the hungry and clothe the naked, said nothing about color."

Canadian authorities encouraged the runaway to settle their vast virgin land.

"I knew the North Star," Henson wrote years later, "Like the star of Bethlehen, it announced where my salvation lay."

"Do you see those trees? They grow on free soil."

If the instructors' sensitivity and awareness of biblical references has been cultivated, they will be able to integrate the above mentioned biblical knowledge into the classroom instruction. As for the famous woman writer Harriet Beecher Stowe and her masterpiece Uncle Tom's Cabin mentioned in Text A, her writing background can be introduced from the perspective of her Christian beliefs. Learners will capture that Uncle Tom, a long suffering slave, did not betray his master though helping other slaves escape because one was commanded by the Bible doctrine to be loyal to his God or his master. Likewise, civil rights heroes like John Parker, Levis Coffin and Josiah Henson are included in Text A, and Martin Luther King is covered in Text B. If the learners 
acquire the relevant knowledge about these culture points, they can fully understand the reason why Parker, Coffin and King turned into civil-rights heroes lies in that these heroes cannot be isolated from their Christian beliefs and the driving force from the Bible. With the culture blank filled in, learners tend to have a better understanding of the reading material, and thus perform much better in process of IC.

\section{Methodology}

\subsection{Research Questions}

This research attempts to incorporate biblical knowledge into ELT, with the purpose of improving the learners' intercultural awareness as well as their ICC. The research aims to throw light on the notion of IC by focusing on learners' acquisition and learning of biblical references, and also contribute to existing literature on the topic. However, the first step of the research is to explore the possibility of improving ICC from the perspective of biblical knowledge. With the aid of a survey, the paper aims to paint a picture of the current situation in the learners' attitude to learning English, their biblical knowledge and conception of the biblical culture. Therefore, four specific questions guiding the current survey are noted as follows:

1) What about freshmen's interest in learning the coursework of College English?

2) What about their perception of the biblical culture in the development of ICC?

3) How much do they know about the biblical references?

4) How do instructors integrate biblical knowledge into their ELT practice?

\subsection{Participants}

A total of 144 participants from 3 English classes in the university where the author works participated in the survey. To qualify for this survey, freshmen of the same age group (between 18 and 20) were selected to be the participants of the research. Brought up in China, they were supposed to share little biblical knowledge in their encyclopedia because Chinese children are scarcely exposed to biblical references in their daily life and school life. What's more, the statistics in terms of Stem-and-Leaf Plot (Appendix 1) showed the normal distribution of English course scores in National College Entrance Exams(hereafter referred to as NCEE), with most participants ranging from 85 to 109 in the total scores of 120 points. This indicates that the participants belong to the same English level, that is the level of above average, and that they have acquired the necessary linguistic knowledge and competence for the research purpose.

\subsection{Data Collection and Analysis}

According to the culture testing methods supported by Gass et al (2011, p. 156-165) and Valette (1977, p. 263-281), the test in this study employed a questionnaire composed of open-ended items, closed-ended items and multiple choices. This method is also used by teachers at home and abroad in culture testing (Moore, 1994; Zou, 2005; $\mathrm{Li}$ et al, 2008). The questionnaire in the survey included 15 questions, with 1 open question about the enrollment scores of English course in NCEE. The open question was included to investigate the participants' English language level, justifying whether they have acquired the necessary linguistic knowledge and competence for the research purpose. Likewise, 9 closed questions were designed on a 4-point Likert scale. Q1-4 aimed to reveal the respondents' interest, willingness, enjoyment, and confidence in learning English. Q5-9 aimed to reveal the respondents' opinions on the importance of biblical knowledge in learning English as well as expectation in learning biblical culture. The last 5 questions were designed into multiple choices to check their biblical knowledge. Five illusions were selected in the questionnaire because they rank among the most commonly exposed in Chinese literature. The data collected were analyzed with SPSS 13.0, aiming to illustrate the first three research questions listed in Section 3.1. Based on the results, the author would then propose a teaching arrangement, aiming to respond to the fourth question.

\subsection{Results and Discussion}

The discussion of the current survey first goes to the first section of the questionnaire. Q1-Q4 would respectively indicate respondents' interest, willingness, enjoyment, and confidence in learning English. Each question was composed of 4 Likert scale items, where A=Very much interested, willing, joyful or confident (scoring 4 points); $\mathrm{B}=$ Interested, willing, joyful or confident (scoring 3 points); $\mathrm{C}=$ Not so interested, not so willing, not so joyful or not so confident (scoring 2 points); $\mathrm{C}=$ Not at all interested, not at all willing, not at all joyful or not at all confident (scoring 1 points). Respondents were asked to indicate the frequency by circling one of Likert items ranging from "A" to "D". The mean, mode and median of frequencies in circling the respective item were analyzed with SPSS 13.0, with the descriptive statistics listed in Table 1. 
Table 1. The current situation in learning English

\begin{tabular}{llrrrr}
\hline & & an1 & an2 & an3 & \multicolumn{1}{c}{ an4 } \\
\hline $\mathrm{N}$ & Valid & 143 & 143 & 143 & 143 \\
& Missing & 1 & 1 & 1 & 1 \\
Mean & & 3.0420 & 3.1748 & 2.6503 & 3.2727 \\
Median & 3.0000 & 3.0000 & 3.0000 & 3.000 \\
Mode & 3.00 & 3.00 & 3.00 & 4.00 \\
Std. Deviation & .63771 & .53490 & .90584 & .74287 \\
Variance & .407 & .286 & .821 & .552 \\
\hline
\end{tabular}

As shown in Table 1, Mode=3.00, Median=3.0000 in Q1, Q2 and Q3 indicated that Item B were circled most by the respondents, and that more than half the respondents circled Item B. Mean=3.0420 (>3.00) in Q1 indicated that Item B was circled most frequently, and a few respondents circled Item A. This explained that more than half the respondents were interested, and a few were strongly interested in learning English. Mean=3.1748 (>3.00) in Q2 indicated that Item B was circled most frequently, and some respondents circled Item A. It would conclude that more than half respondents were willing to and some were strongly willing to spend extracurricular time in studying English. Mean=2.6503 $(<3.00)$ in Q3 indicated that though Item B was circled most frequently, still many respondents circled Item C or D so that the mean score reached only $2.6503(<3.00)$. This showed that although more than half the respondents enjoyed or strongly enjoyed learning English, quite many painfully enjoyed or even suffered from learning. As for Q4, Mode $=4.00$, Median=3.000 indicated that though Item A were circled most frequently, quite some respondents circled Item B. However, Mean=3.2727 (>3.00) indicated that still quite many respondents circled Item B or other items so that the mean score reached only $3.2727(<4.00)$. This followed that most respondents showed strong confidence and some showed confidence or not so much confidence in improving their English. Anyhow, the survey based on the above four questions provides evidence to the positive and upward tendency among the respondents in terms of their interest, expectation, confidence in improving their English, though even some were painfully enjoying or suffering from the process.

The survey would then turn the attention to another part, from Q5 to Q9. These five questions illustrate respondents' perception of the western culture and biblical culture. Q5 to Q9 were respectively designed on the 4-point Likert scale of agreement and expectation, where $\mathrm{A}=$ Very much helpful or hopeful or agreeable (scoring 4 points), $\mathrm{B}=$ Helpful or Hopeful or Agreeable (scoring 3 points), $\mathrm{C}=$ Not so helpful or hopeful or agreeable (scoring 2 points), $\mathrm{D}=$ Not at all helpful or hopeful or agreeable (scoring 1 point). Respondents were asked to indicate the frequency by circling one of the Likert items. The mean, mode and median of frequencies in circling the respective items were analyzed with SPSS 13.0, as illustrated in Table 2.

Table 2. Respondents' perception of western culture and biblical culture

\begin{tabular}{llrrrrr}
\hline & & an5 & an6 & an7 & an8 & an9 \\
\hline $\mathrm{N}$ & Valid & 143 & 143 & 143 & 143 & 143 \\
& Missing & 1 & 1 & 1 & 1 & 1 \\
Mean & & 3.6503 & 3.5385 & 3.0699 & 3.2308 & 2.7762 \\
Median & & 4.0000 & 4.0000 & 3.0000 & 3.0000 & 3.0000 \\
Mode & 4.00 & 4.00 & 3.00 & 3.00 & 3.00 \\
Std. Deviation & .60815 & .57860 & .64623 & .64669 & .63267 \\
Variance & .370 & .335 & .418 & .418 & .400 \\
\hline
\end{tabular}

As for Q5 an Q6, mode $=4.00$ and median $=4.0000$ indicated that Item A were circled most by the respondents, more than half the respondents circling Item A. Mean=3.6503 (>3.00) in Q5, Mean=3.5385 (>3.00) in Q6 indicated that vast majority of the respondents thought that the western culture knowledge was helpful and very much helpful for learning English, and that they expected or strongly expected teachers to integrate the knowledge in the classroom instruction. As shown in Table 2, Mode=3.00 and Median=3.0000 in Q7, Q8 and Q9 indicated that Item B were circled most by the respondents and more than half the respondents circled Item B. Mean=3.0699 (>3.00) in Q7 showed that though Item B was most frequently circled, only a few respondents circled Item A. Mean=3.2308( $>3.00)$ in Q8 indicated quite many respondents circled Item A. Mean=2.7762 $(<3.00)$ in Q9 indicated that though even Item B was most frequently circled and more than half the respondents 
circled Item B and A, still quite many respondents circled Item C and even D. The results lead to the conclusion that the respondents' perception of the Bible culture did not accord with their perception of the western culture. Though the vast majority agreed and some strongly agreed to the important role that western culture played in learning English language, they did not fully perceive the important role of the biblical culture in learning English language. More than half the respondents agreed to, instead of strongly agreed to, the benefit of biblical knowledge in learning English, and they showed only average desire for learning biblical knowledge. And a large number did not agree to the idea that the Bible is the core of western culture.

What follows then is the analysis of the last section, from Q10 to Q14 in the questionnaire, which was designed on the basis of multiple choices. Respondents who circled the correct answer would score 1 point, otherwise they would score 0 point. The sum of scores on Q10 to Q14 was computed with SPSS 13.0, and then the mean of the sum was tested in the order of One-Sample T Test, with the test value $=3$, as illustrated in Table 3 .

Table 3. One-Sample Test of the mean value in biblical knowledge

One-Sample Test

Test Value $=3$

\begin{tabular}{ccccccccccc}
\hline \multicolumn{1}{c}{} & \multicolumn{1}{c}{ Std. Error } & & & & & \multicolumn{2}{c}{$\begin{array}{c}95 \% \text { Confidence Interval } \\
\text { of the Difference }\end{array}$} \\
$\mathrm{N}$ & Mean & Mean & Std. Deviation & $\mathrm{t}$ & $\mathrm{df}$ & $\begin{array}{c}\text { Sig. } \\
\text { (2-tailed) }\end{array}$ & Difference & Lower & Upper \\
\hline 142 & 2.5563 & .09189 & 1.09496 & -4.828 & 141 & .000 & -.44366 & -.6253 & -.2620 \\
\hline
\end{tabular}

As shown in Table 3, $\mathrm{t}=-4.828$, and Sig. $(2$-tailed $)=.000(<0.05)$ indicated that there was significant difference between the mean value and the test value. Mean=2.5563 $(<3)$, and the minus $t$ value showed the mean value was lower than the test value 3. Besides, no value of 0 was included between the lower limit $=-.6253$ and the upper limit $=-.2620$. Hence the survey has $95 \%$ confidence to reach the conclusion that respondents have grasped less biblical knowledge than expected. Thus, the paper argues for an urgent need to educate them about the theories mentioned and improve their perception of the biblical culture in learning English.

Referring back to the data analyses, it is concluded that the respondents have fully perceived the importance of western culture in learning English and they do expect to be educated about it. Though these respondents have somewhat acknowledged the core position of the Bible in western culture, they do not show a strong expectation of learning the Bible references, social values and behavior criteria addressed in the Bible, etc. Likewise, they have grasped less biblical knowledge than expected. This prevents cultivating ICC in learners, since effective ICC comes from learners' language skills, cultural perceptions and cultural awareness. A clear picture of the exotic culture helps to capture the communicative partner's social belief, social value and the like. To some extent, justifying the learners' perception of the Bible's core position in western culture and educating them about biblical knowledge remains an urgent and meaningful job, but tough too.

\section{Pedagogical Improvements}

ICC has been an indispensable part of ELT, and cultivating and improving learners' ICC is the ultimate purpose and the very significance of this research. Cultivating ICC from the perspective of integrating biblical knowledge into ELT is not just a theoretical matter, but a practical issue. Hence, the practice is first of all based on the survey, offering a map of the current situation in learners' perception of biblical knowledge in learning English. Likewise, a theoretical background about culture and language is necessary, otherwise both instructors and learners could not have the justified perception and motivation in doing this tough job.

Learning biblical culture brings students closer to understanding how the people in Christian culture think, what motivates them, and what colors their perception of the world around. Reflecting on the material and on the outcome of analysis may result in a new research question (Wester et al, 2000), and the question here becomes how to integrate biblical knowledge into ELT. ELT involves the development of linguistic proficiency, imparting the linguistic knowledge and cultivating intercultural awareness, whose unique features set up demanding requirements for the instructors (Wang, 2011). Kanno et al (2011) also argue for the need to include a deeper understanding of teacher identity development in the knowledge base of second language teacher education. The instructor, as a bridge between learners and course books, should transform themselves from the passive role of teaching to the active role of exploring and interpreting course books. It then occurs to the author that how to 
integrate biblical knowledge into ELT falls upon the shoulders of instructors.

Except for the teaching practice exemplified in Section 2.3, tips for how to effectively teach biblical references are numerous, only to name a few in the following:

1) The instructor first should give some lectures on different topics, such as introduction to the Bible, the Bible's influences on western literature, religion, art, music and architecture etc. If class hours are not sufficient, the instructor can upload the relevant materials to his/her students.

2) The instructor then should create his/her own website, and the like, where the collected materials can be shared among the instructor and learners.

3) Movies of the biblical topic are also provided for an easy access, since movies appeal to the college students in the age group of $18-20$.

4) Classroom warming-up activities or small plays related to the topic are necessary in the instruction process to highlight the teaching effectiveness.

To sum up, the necessary connection between awareness and learning has long been noted, and empirical investigations of the second language learning have found no evidence of learning without awareness (Leung et al, 2011). The acquisition of biblical knowledge as well as western culture mainly depends on the cultural sensitivity and awareness, as well the perception of culture, social values and social beliefs. Last but not least, the process of integrating biblical knowledge into ETL could arouse the learners' interest in such cultural knowledge as proverbs, folk tales, legends, myths, art, etc. In this way, learners' cultural sensitivity and awareness will be strengthened and their ICC could be cultivated and improved from the real sense. That makes the ultimate purpose of this research and the ultimate goal of ETL.

\section{Conclusion}

According to the survey, a positive and upward tendency was shown among the respondents in terms of their interest, expectation, confidence in improving their English, though even they were not very much enjoying but painfully enjoying the process. Secondly, they did not fully perceive the important role of biblical culture in learning English language and acquiring ICC. Thirdly, One-Sample Test of the sum scores in their biblical knowledge provided the survey with $95 \%$ confidence to conclude that respondents had grasped less biblical knowledge than expected. These major findings would appear to give answers to the first three research questions. Then, pedagogical improvements were addressed in the paper, such as affecting teaching materials, giving lectures, watching movies and performing warming-up activities, aiming to give answers to the last research question. Last but not least, this survey claims that biblical knowledge serves as a trigger in the research, aiming to develop learners' cultural sensitivity and awareness in the broad sense since culture shapes language.

\section{Acknowledgements}

This paper is a phased achievement of the research, entitled 'Studies on the Assessment System of Intercultural Communicative Competence in College Students (No. 12BYY056). The program is subsidized by the National Social Science Research Fund 2012. And my sincere gratitude goes to Professor Yongchen Gao for her generous help and constant encouragement.

\section{References}

Damen, L. (1987). Culture Learning: The Fifth Dimension of Language Classroom. New Jersey: Addison-Wesley Publishing Company.

Gass, S. M., \& Mackey, A. (2011). Data Elicitation for Second and Foreign Language Research. New York: Routledge/Beijing: Foreign Language Teaching and Research Press.

Hall, E. T. (1976). Beyond Culture. New York: Doubleday.

Hu, W. Z. (2005). On Empirical Research in Intercultural Communication. Foreign Language Teaching and Research, 2005(3), 324-327. http://dx.doi.org/1000-0429(2005)05-0323-5

Hu, Y. (2011). An Empirical Study on College Students' Intercultural Sensitivity. Journal of the Foreign Language World, 2011(3), 68-73. http://dx.doi.org/1004-5112(2011)03-0068-06

Kanno, Y., \& Stuart, C. (2011). Learning to Become a Second language Teacher: Identity-in-Practice. The Modern Language Journal, 95(2), 236-252. http://dx.doi.org/10.1111/j.1540-4781.2011.01178.x

Leung, J. H. C., \& Williams, J. N. (2011). The Implicit Learning of Mappings between Forms and Contextually Derived Meanings. Studies in Second Language Acquisition, 33(1), 33-55. 
http://dx.doi.org/10.1017/S0272263110000525

Li, P., \& Liu, A. Z. (2008). Constructs and test of cultural knowledge as a Component of intercultural communicative competence. Journal of Inner Mongolia Agricultural University (Social Science Edition), 2008(3), 107.

Moore, Z. T. (1994). The Portfolio and Testing Culture. In C. R. Hancock (Ed.), Teaching, Testing and Assessment: Making the Connection. Northeast Conference Reports. Lincolnwood, IL: National Textbook.

Peng, S. Y. (2005). Intercultural Communication Research in China: Status Quo, Problems, and Suggestions. $\begin{array}{llll}\text { Journal of Hunan University(Social } & \text { Sciences), } & 2005(7), & 86-91 .\end{array}$ http://dx.doi.org/1008-1763(2005)04-0086-06

Samovar, L. A., Porter, R. E., \& Stefani, L. A. (2000). Communication Between Cultures. Beijing: Foreign Language Teaching and Research Press, Brooks/Cole/Thomson Learning Asia.

Sapir, E. (1921/2000). Language: An Introduction to the Study of Speech. New York: Harcourt, Brace/New York: Bartleby Company.

Valette, R. M. (1977). Modern Language Testing (2nd ed.). New York: Harcourt, Brace, Jovanovich.

Wang, S. R. (2011). Some Thoughts on College English Teaching in China. Foreign Language Learning Theory and Practice, 2011(1), 1-5.

Wester, F., \& Peters, V. (2000). Qualitative Analysis: Phase, Techniques and Computer Use. In C. J. Pole \& R. G. Burgess (Eds.), Cross-Cultural Case Study (pp.139-164). New York: Elsevier Science Inc.

Zhang, H. L. (2010). A Summary of the 2010 Chinese Intercultural Disciplinary Development Symposium. Journal of Foreign Language, 2010(6), 49-53. http://dx.doi.org/1004-5139(2010)06-0049-05

Zhou, Q., \& Cai, L. Q. (2010). Foreign Linguistic Studies in China from 2007 to 2009: A Statistic Analysis of Papers Published on Six Major Journals of Foreign Language Studies. Foreign Language Research, 2010(5), 51-56. http://dx.doi.org/1005-7242(2010)05-0051-06

Zou, S. (2005). Language Testing. Shanghai: Shanghai Foreign Language Education Press.

\section{Appendices}

Appendix 1:

Frequency distribution of the enrollment scores in English course (Stem-and-Leaf Plot)

\begin{tabular}{rll}
\hline $\begin{array}{c}\text { Stem - and - Leaf } \\
\text { Plot }\end{array}$ \\
Frequency \\
Stem \& Leaf \\
1.00 & 6. & 8 \\
2.00 & 7. & 14 \\
8.00 & 7. & 55557888 \\
15.00 & 8. & 001222333334444 \\
31.00 & 8. & 5555555555566778888899999999999 \\
21.00 & 9. & 000001123334444444444 \\
26.00 & 9. & 55555556666666777778888888 \\
21.00 & 10. & 000001111222222333344 \\
15.00 & 10. & 555556777778889 \\
3.00 & 11. & 001 \\
\hline Stem width: 10.00 & \\
Each leaf: $\quad 1$ case(s)
\end{tabular}




\section{Appendix 2:}

\section{Questionnaire}

School

Major

Grade

This questionnaire attempts to know about the freshmen's current situation in learning English as well as their conception and knowledge about the western culture. You're invited to participate in the survey, and you may rest assured that results of the survey will be used for academic research only, irrelevant to the grading of the course study. Thank you for you cooperation!

( ) You scored in the English course during the College Entrance Exam, with full marks of

( ) 1) Are you interested in learning English?
A) Very much interested
B) Interested
C) Not so interested
D) Not at all interested

( ) 2) Are you willing to spend more extracurricular time in learning English?
A) Very much willing to
B) Willing to
C) Not so willing to
D) Not at all willing to

( ) 3) What do you feel about learning English?
A) Very much joyful
B) Joyful
C) Painfully joyful
D) Rather painful

( ) 4) Do you have confidence in improving your English?
A) Very much confident
B) Confident
C) Not so confident
D) Not at all confident

( ) 5) Do you think that western culture knowledge is helpful for learning English?
A) Very much helpful
B) Helpful
C) Not so helpful
D) Not at all helpful

( ) 6) Do you expect your teacher to introduce the relevant western culture into the classroom?
A) Very much hopeful
B) Hopeful
C) Not so hopeful
D) Not at all hopeful

( ) 7) Do you think that biblical knowledge might be helpful for learning English?
A) Very much helpful
B) Helpful
C) Not so helpful
D) Not at all helpful

( $\quad$ ) Do Dou hope your teacher to introduce relevant biblical knowledge into the classroom?
A) Very much hopeful
B) Hopeful
C) Not so hopeful
D) Not at all hopeful

( ) 9) Do you agree to the idea that the Bible is the core of western culture and literature?
A) Very much agreeable to
B) Agreeable to
C) Not so agreeable to
D) Not at all agreeable to 
( ) 10) Where do you know the allusion "dove and olive branch" comes from?
A) Geek mythology
B) Chinese ancient mythology
C) The Bible
D) Latin mythology

( ) 11) Where do you know the allusion "wash one's hands" comes from?
A) Geek mythology
B) Chinese ancient mythology
C) The Bible
D) Latin mythology

( ) 12) How did God create humans according to the Bible?
A) Ribs
B) Clay
C) Animal meet
D) Sands

( ) 13) What profession does the allusion “Adam's profession" refer to?
A) Priest
B) Gardener
C) Fisherman
D) Businessman

( ) 14) What do you mean by the allusion "scapegoat"?
A) Escaping punishments
B) Escaping responsibilities
C) Punished for others faults
D) Goddess of Luck 